\title{
Anatomy and Histology of Digestive Tract in Melanophila (Trachypteris) picta decastigma (Fabricius, 1787) (Coleoptera: Buprestidae)
}

\author{
Nurcan Ozyurt Kocakoglu' ${ }^{\mathbb{D}}$, Uzeyir Caglar ${ }^{2} \mathbb{D}^{\text {, Selami Candan }}{ }^{1}$ \\ 'Gazi University, Science Faculty, Department of Biology, Ankara, Turkey \\ ${ }^{2}$ Gazi University, Vocational School of Health Services, Ankara, Turkey
}

ORCID IDs of the authors: N.O.K. 0000-0001-7137-8631; U.C. 0000-0002-8401-0155; S.C. 0000-0002-7402-1360

Please cite this article as: Ozyurt Kocakoglu N, Caglar U, Candan S. Anatomy and Histology of Digestive Tract in Melanophila (Trachypteris) picta decastigma (Fabricius, 1787) (Coleoptera: Buprestidae). Eur J Biol 2021; 80(1): 1-8.

DOI: 10.26650/EurJBiol.2021.800131

\section{ABSTRACT}

Objective: The aim of this study is to investigate the anatomy and histology of Melanophila picta decastigma (Fabricius) (Coleoptera: Buprestidae).

Materials and Methods: Some of the samples were fixed in 10\% formaldehyde for light microscopy, others were fixed with $2.5 \%$ glutaraldehyde for scanning electron microscopy (SEM). Then the samples were examined by using stereo, light, and SEM.

Results: The digestive tract in M. picta decastigma consists of foregut, midgut, and hindgut. The foregut is composed of the pharynx, esophagus, crop and proventriculus. The foregut showed muscle layers followed by intima and epithelium. There is a long, tubular pair of gastric caeca in the anterior part of the midgut. In cross-sections, a single-layered cylindrical epithelium with a short striated border. The midgut showed that the epithelial lining was substantially folded, giving its lumen a curved profile. These monolayered columnar epithelial cells had their nuclei located medially, and apically they have a striated border. The midgut surface was covered by rounded structures called regenerative crypts. The main sections of hindgut (pyloric valve, ileum, colon and rectum) were clearly observed. In the hindgut sections, there appeared to be a highly folded cuticular lining, a monolayer cubic epithelium and a very muscular wall.

Conclusions: Studies on the digestive tract histo-anatomy of M. picta decastigma will add more information to assist in experimental, taxonomical, histological, and anatomical studies about insect tissues and will serve as a basis for control studies.

Keywords: Foregut, midgut, hindgut, Malpighian tubules, light microscope, electron microscope

\section{INTRODUCTION}

Buprestidae is a family of insects known as gem beetles or metallic wood boring insects because of their bright iridescent color. The Buprestidae has 5,000 known species in 450 genera and it is the eighth largest family of Coleoptera with many extant common buprestids (1-3). Buprestidae (4\% of Coleoptera) are all widespread terrestrial groups (4). There are many dangerous pests of fruit trees, forest trees, shrubs and herbaceous plants among the Buprestidae (5). Most Buprestidae family species are in the secondary pest status, but when they reproduce in large quantities and cannot find enough food sources to suit their wishes, they become primary pests and cause a lot of damage to the trees. Therefore, the Buprestidae family is considered to be an important family in forestry, covering many harmful species (6). Melanophila is a genus of buprestid beetles commonly known as fire beetles (7). Most of them are found in the Mediterranean environment, the Middle East and Europe (8). The majority of the adult buprestid beetles 
including Melanophila beetles are diurnal, sun-loving, and oligophagous (9). The damage status of Melanophila decastigma on poplars has been reported to have a positive correlation between disease and pests (10). These pests attack many poplars in physiologically weakened conditions and cause considerable damage in nurseries, plantations and wood-lots (11).

The digestive tract of all insects is an epithelial tube that follows a straight or curved path from mouth to anus and consists of three separate parts: the foregut and hindgut arising as the ectodermal, but the midgut is endodermal in origin (12-16). The gut epithelium is a single cell-layer thick throughout the length of the alimentary canal and rests on a basement membrane surrounded by a variably developed muscle layer (17). In Coleopteran insects including Buprestidae, the foregut is usually short and subdivided into four distinct regions including a pharynx, an esophagus, a crop (food storage region) and the proventriculus (a grinding organ). The midgut is covered with small, regenerative crypts. There is a pair of caeca between the foregut and the midgut. The hindgut is equal to or greater than the length of the midgut. The hindgut has narrow small and larger intestines. The digestive tract ends in a rectum. The six cryptonephric Malpighian tubules join with the pyloric valve, between the midgut and hindgut (18). The foregut is responsible for the ingestion, storage, grinding and transport of nutrient to the midgut. Digestive enzymes are produced and secreted in the midgut, and digestion products are absorbed. Material remaining in the intestinal lumen along with urine from the Malpighian tubules then enters the posterior intestine, where the absorption of water, salts and other valuable molecules occurs before the feces are expelled from the anus. Coleoptera has a cryptonephric system in which the distal ends of the Malpighian tubules are held in contact with the rectal wall by the perinephric membrane. Such an arrangement allows some beetles that live on a very dry diet, such as stored grain, to be extraordinarily efficient in their conservation of water (17).

The digestive system of Melanophila picta decastigma, which is an important pest species, was examined anatomically and histologically since there have been no previous studies of the digestive tract of Melanophila genus. With this study, it is thought that the Buprestidae family including Melanophila genus and other Coleopterans will contribute to the digestive system histology and anatomy, and thus, basic information will be provided for studies to combat these harmful species.

\section{MATERIALS AND METHODS}

\section{Insects}

Adult specimens of $M$. picta decastigma $(n=20)$ were collected at 39.255940E, 32.961942N in the Kömüşini, Kulu, Konya, Turkey in May 2019.

\section{Preparation of Gut}

For light microscope examinations, adult insects were anesthetized with ethyl acetate and dissected in $0.1 \mathrm{M}$ sodium phosphate buffer solution ( $\mathrm{pH} 7.2)$ under the stereomicroscope (Olympus SZX7). Any surrounding fat was removed. The spec- imens were fixed in $10 \%$ formaldehyde, and then they were dehydrated with graduated ethanol series. Then, specimens were cleaned by xylene and embedded in pure paraffin and sectioned (6-7 $\mu \mathrm{m}$ thick) via a Microm microtome. They were stained with hematoxylin and eosin (H\&E). These sections were photographed under a light microscope (Olympus BX51).

\section{Scanning Electron Microscopy (SEM)}

For SEM examinations, the dissected guts were fixed with $2.5 \%$ glutaraldehyde ( $\mathrm{pH} 7.2$, sodium phosphate buffered), washed three times with phosphate buffer ( $\mathrm{pH} 7.2)$ for 15 minutes, and then dehydrated in ethanol series (70-100\% for 15 min each). Then tissues were dried with Hexamethyldisilazane (HMDS), and they were mounted by double-sided tape on SEM stubs, and then coated with gold for 2 minutes with a Polaron SC 502 sputter coater. The samples were examined with a JEOL (JSM $6060 \mathrm{LV}$ ) SEM operated at $10 \mathrm{kV}$, and photographed in an electron microscope laboratory in the faculty of science at Gazi University.

\section{RESULTS}

In M. picta decastigma adults, the digestive tract is a long tube (Figure 1a). The digestion starts from the mouth (Figure 1b). The mouth parts generally consist of a pair of maxillary palps, a pair of labial palps, a mentrum, a submentrum, and a gula (Figure 1b). Muscle bundles were seen in the lower part of the head, anterior to the esophagus (Figure 1c). The digestive tract consisted of three basic regions, that is, fore, mid, and hindgut. The foregut and hindgut were almost equal in length, but the midgut was shorter than the other parts (Figure 1a). The foregut is composed of the pharynx, esophagus, crop and proventriculus (Figures 1a, d). The pharynx is the first part of the foregut, which connects the mouth with the esophagus. The esophagus was a simple, long tube connecting the pharynx with the crop (Figures 1a, d). Anatomically, the esophagus was surrounded by transverse and longitudinal muscle layers, and trachea and tracheoles were found on the muscle layer (Figure 1e). Histologically, the esophagus was composed of the lumen, intima, a single layer epithelium and muscle layer from the inside out (Figure 2a). On the inner surface of the intima of the esophagus, there were sometimes protrusions in the form of spines, sometimes in the form of blunt-tipped teeth (Figures $2 b-d$ ). The crop was located just behind the esophagus. The crop contains a series of longitudinal and transverse muscle layer bundles just outside the epithelium (Figure 3a). The epithelial cells, which are mono-layered and cubic, formed the tissue just outside the intima in the crop. There were oval nuclei of epithelial cells medially (Figure 3a). Food particles were distinguished in the lumen. Spiny protrusions in groups were observed on the inner surface of the intima layer. Food particles were found among these spiny protrusions (Figure 3b).

The proventriculus is a thick-walled region lying just posterior to the crop, called a grinding organ. Histologically, the proventriculus was from the inside out, the lumen was filled with food particles, the intima with sharp protrusions, the single-layered 

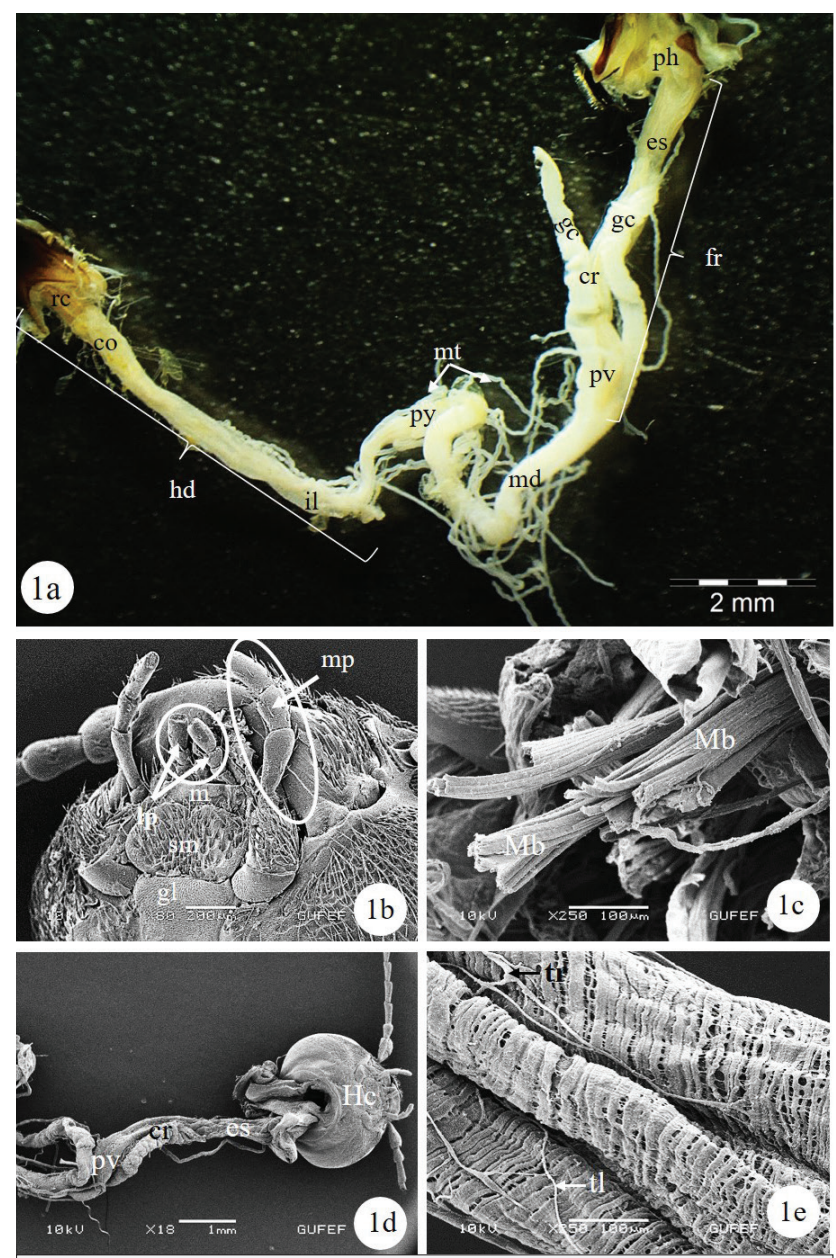

Figure 1. a. The general view of digestive tract in M. picta decastigma (SEM). b. SEM photograph of the general view of mouth structure. $\mathbf{c}$. The muscle bundles around the esophagus (SEM). d. SEM photograph of the foregut parts. e. Longitudinal and transverse muscles surrounding the esophagus. Abbreviations: co-colon, cr-crop, es-esophagus, fr-foregut, gcgastric caecum, gl-gula, Hc-head capsule, hd-hindgut, il-ileum, Ip-labial palp, Mb-muscle bundle, md-midgut, m-mentrum, mp-maxillary palp, mt-Malpighian tubules, ph-pharynx, pvproventriculus, py-pyloric valve, rc-rectum, sm-submentrum, tl-tracheole tr-trachea.

cubic epithelium with spherical nuclei medially, surrounded by a longitudinal and transverse muscle layer (Figures $3 c$ and $d$ ). There were spiny structures with very long protrusions in the intima layer. Food particles of different sizes were seen between these spiny protrusions (Figures $3 e$ and $f$ ).

There was a long, tubular pair of gastric caeca in the anterior part of the midgut, which is the second part of the digestive tract. Anatomically, the gastric caecum surface was seen as round protrusions resembling corn grains (Figures $4 a$ and b). Trachea and tracheoles in the form of thin threads were found on these structures (Figure 4a). In cross-sections, a single-layered cylindrical epithelium with a short striated border at its apex was distinguished. The epithelium layers were convoluted

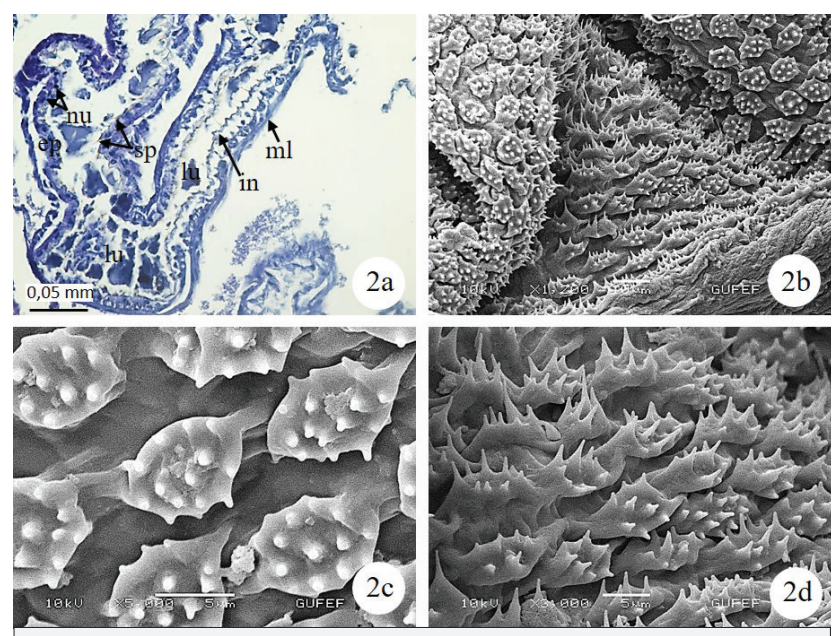

Figure 2.Lightmicroscopy and SEM photographs of the esophagus in M. picta decastigma. a. Longitudinal section of the esophagus (H\&E) (LM). b. The protrusions in the spines and blunt-tipped teeth form in the esophagus intima (SEM). c. SEM photograph of food particles on blunt-tipped teeth groups. $d$. Spine groups in the intima of the esophagus (SEM). Abbreviations: ep-epithelium, in-intima, lu-lumen, ml-muscle layer, nu-nucleus, sp-spine.
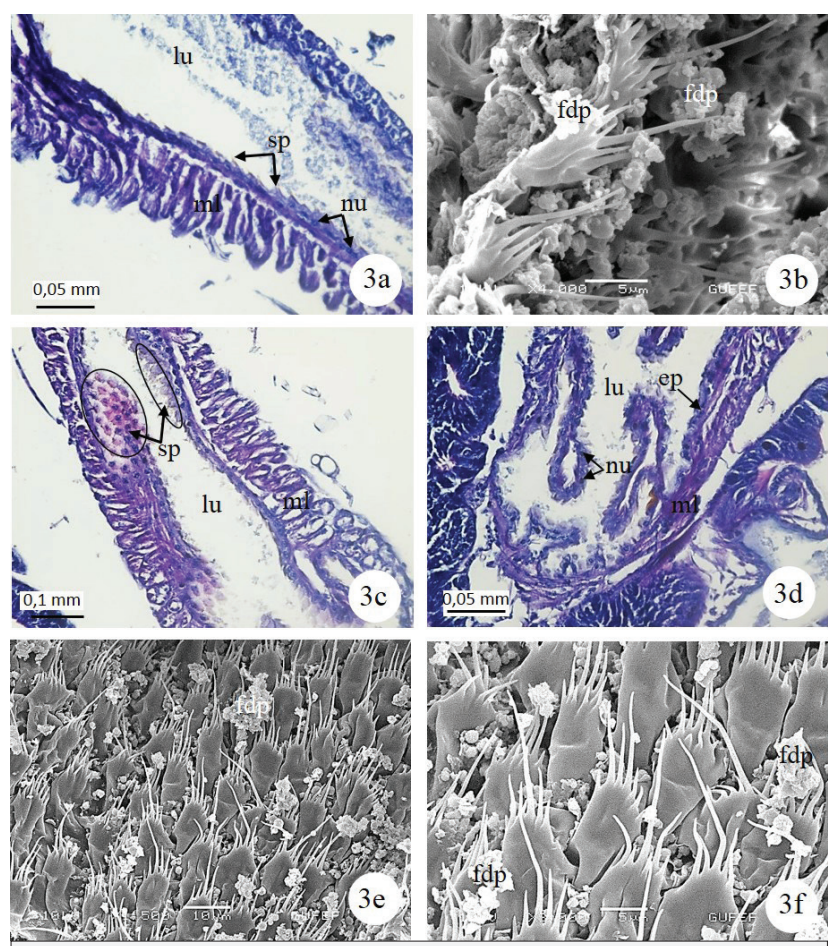

Figure 3. Light microscopy and SEM photographs of the crop and proventriculus in $M$. picta decastigma. a. Longitudinal section of the crop (H\&E) (LM). b. Spiny protrusions on the inner surface of the crop intima layer (SEM). c. Longitudinal section of proventriculus (H\&E) (LM). d. SEM photograph of spiny structures with very long protrusions in the proventriculus intima layer. e. Muscle layer, intima and epithelium surrounding the proventriculus (H\&E) (LM). f. High magnification of the food particles around the spiny structures (SEM). Abbreviations: epepithelium, fdp-food particles, lu-lumen, ml-muscle layer, nunucleus, sp-spiny protrusions. 


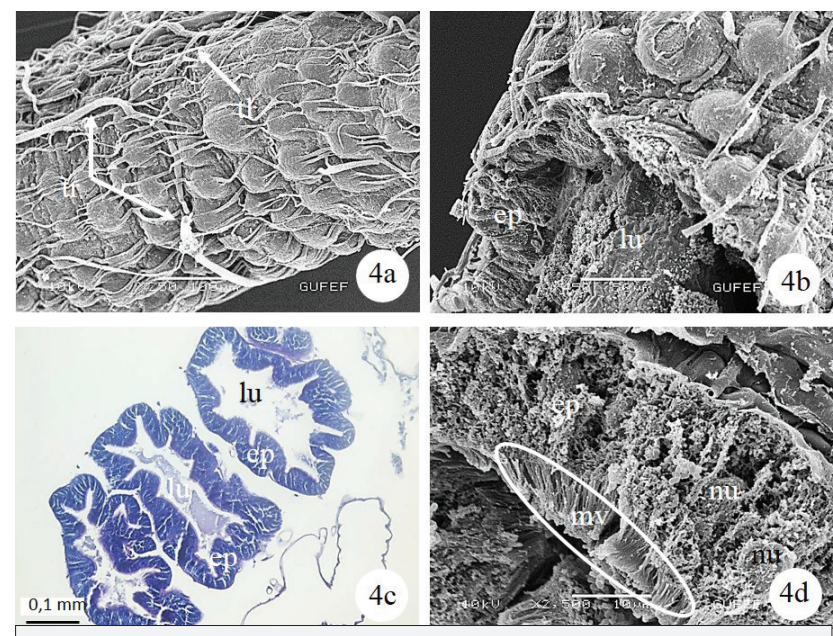

Figure 4. Light microscopy and SEM photographs of the gastric caecum in M. picta decastigma. a. Histological section of the gastric caecum (H\&E) (LM). b. SEM photograph of protrusions resembling corn grains on the gastric caecum surface. c. The epithelial layer surrounding the gastric caecum (SEM). d. SEM micrograph showing microvilli in the apex of the epithelial cells of the gastric caecum. Abbreviations: ep-epithelium, lu-lumen, mv-microvilli, nu-nucleus, tl-tracheole, tr-tracheoles.

in shaped (Figure 4c). SEM micrographs showed microvilli in the apex of the epithelial cells of the gastric caecum (Figure $4 d$ ).

The midgut was a slightly tortuous tube, and it was shorter than the foregut and hindgut. LM and SEM images of the transverse sections of the midgut indicated that the epithelial lining was greatly folded giving its lumen a convoluted profile (Figures 5a and b). These mono-layered columnar epithelial cells had their nuclei located medially, and apically they had a striated border (Figures $5 \mathrm{a}$ and $\mathrm{c}$ ). The outer surface of the midgut was covered with regularly spaced rounded structures, which are called regenerative crypts and responsible for providing a continuous supply of new cells for the epithelial lining of the midgut (Figure $5 d$ ). Some of the regenerative crypts surrounding the midgut were seen in direct contact with the epithelium lining the lumen of the midgut (Figure $5 c$ ). The outer wall consisted of a thin muscle layer beneath which is a convoluted line that completely encircled the midgut (Figure $5 c$ ). The microvilli were seen in the apex of the epithelial cells at high magnifications (Figures $5 \mathrm{e}$ and f). The microvilli were grouped in threads, and they are responsible for absorption.

Anatomically, the proximal ends of the six Malpighian tubules were located between the mid and hindgut. They were divisible into two groups; the first group consisted of four tubules and the second consisted of two tubules (Figures $6 a$ and b). They were highly tortuous tubes, and they had smooth surfaces (Figures $6 a-c)$. The tracheae and tracheoles were seen between the Malpighian tubules (Figures $6 \mathrm{c}$ ). These tubules were made up of 5-6 cells with large oval nuclei, and the epithelial layer had microvilli. A thin layer of connective tissue surrounded these cells (Figures $6 \mathrm{c}$ and $\mathrm{d}$ ).
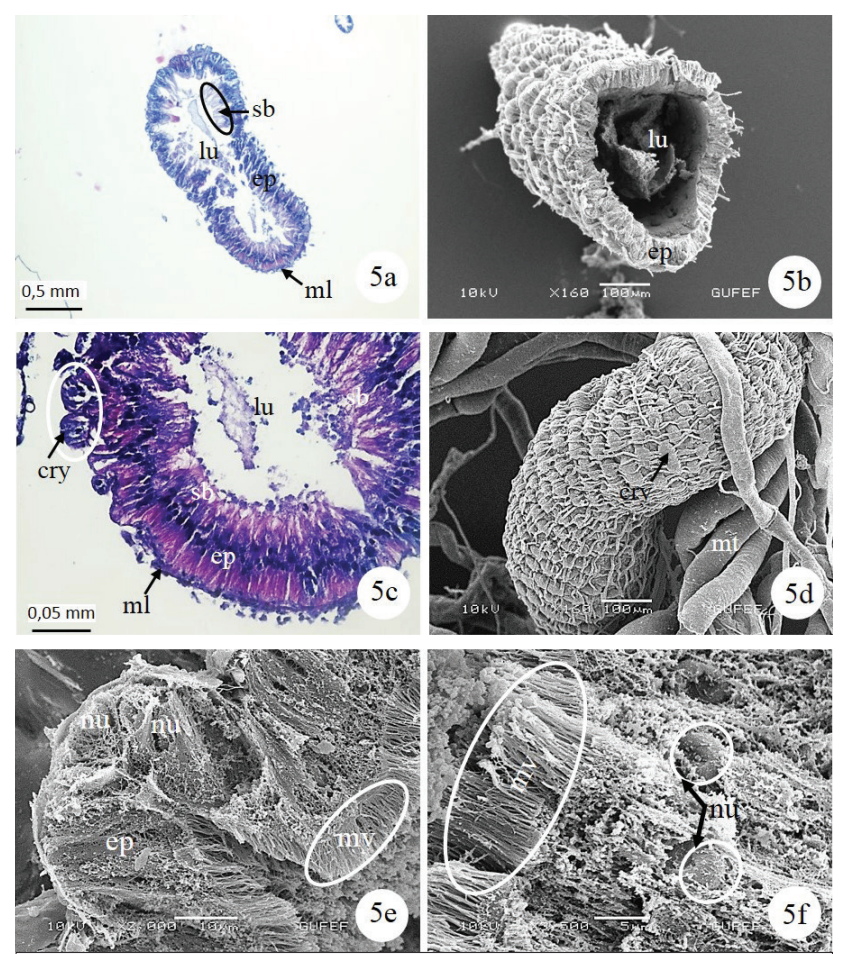

Figure 5. Light microscopy and SEM photographs of the midgut in M. picta decastigma. a. Longitudinal section of the midgut (H\&E) (LM). b. The monolayered columnar epithelial cells surrounding the midgut (SEM). c. The cross section of some regenerative crypts, which are seen in direct contact with the midgut epithelium (H\&E) (LM). d. SEM photograph of the outer surface of the midgut covered with regularly spaced rounded structures, which are called regenerative crypts. e, f. SEM photograph of a single layered columnar epithelial cells which have their nuclei located medially, and apically they have microvilli. Abbreviations: cry-crypt, ep-epithelium, lu-lumen, mt-Malpighian tubule, mlmuscle layer, mv-microvilli, nu-nucleus, sb-striated border.

The hindgut comprised slightly more than one-third of the total length of the gut. The main sections of the hindgut (pyloric valve, ileum, colon and rectum) were clearly observed. In sections of the ileum, a highly folded cuticular lining, a monolayer cubic epithelium and a very muscular wall were seen (Figure $6 d)$. In the epithelial cells, the nucleus was round and located in the center of the cell (Figure $6 \mathrm{~d}$ ). The intima in this region had spines in groups (Figures $6 \mathrm{e}$ and $\mathrm{f}$ ). The epithelial layer of the ileum was thicker than those surrounding the other parts of the hindgut (Figures 6d, 7c and 8b).

The colon linked the distal end of the ileum with the proximal end of the rectum (Figure 7a). The distal ends of the Malpighian tubules in M. picta decastigma were in contact with the colon surface constituting its excretory or cryptonephric system (Figures $7 \mathrm{~b}$ and $\mathrm{c}$ ). The colon had a star-shaped lumen. In cross sections of the colon, the lumen, intima, convoluted single-layered cubic epithelium, Malpighian tubules and sheath were distinguished from inside to outside, respectively (Figures $7 c$ and d). 

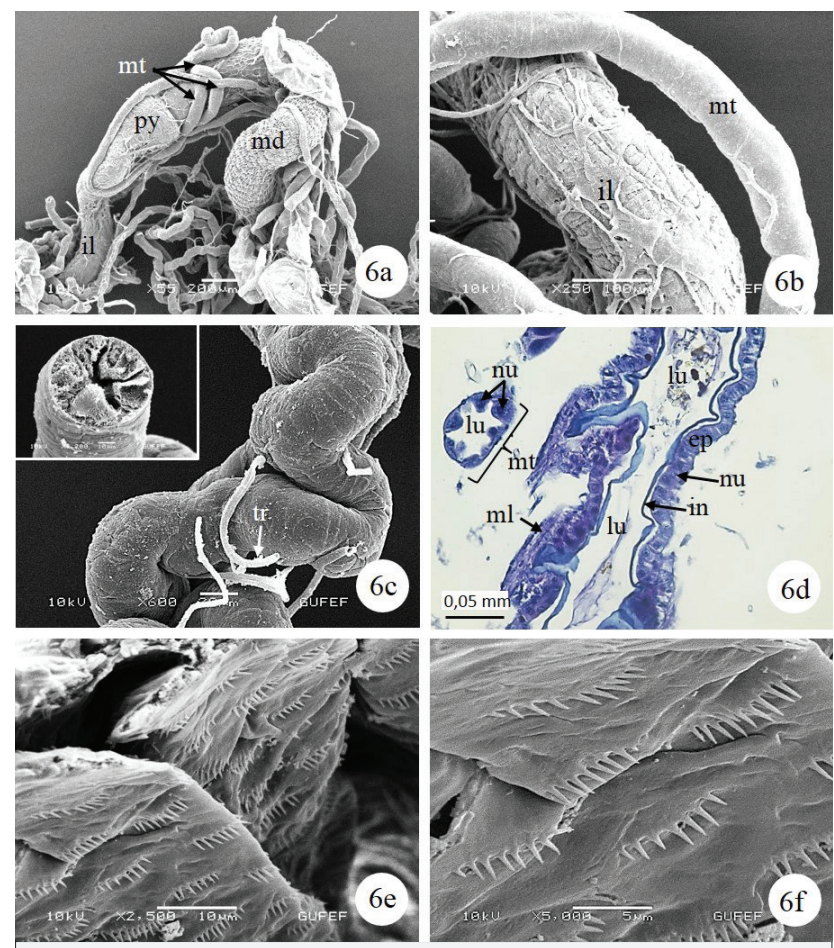

Figure 6. Light microscopy and SEM photographs of the ileum and Malpighian tubules in M. picta decastigma. a. Malpighian tubules, which are located between the mid and hindgut. b. The cubic epithelial cells and sheath surrounding Malpighian tubules, which are smooth surfaced and tortuous tube shaped (SEM). c. Longitudinal section of the ileum (X400) (H\&E) (LM). d. Surface view of the ileum and Malpighian tubules (SEM). e, f. SEM photographs of spine groups in the intima layer. Abbreviations: ep-epithelium, il-ileum, in-intima, lu-lumen, md-midgut, ml-muscle layer, mtMalpighian tubule, nu-nucleus, py-pylorus, tr-trachea.
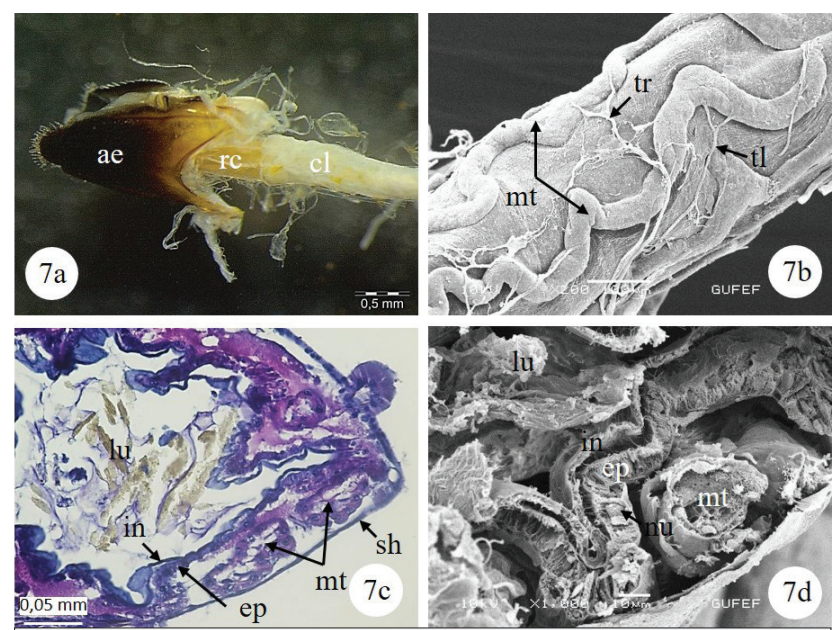

Figure 7. Light and SEM photographs of the colon in M. picta decastigma. a. The general view of the colon, rectum and aedeagus (SM). b. Malpighian tubules, which are in contact with the colon surface (SEM). c, d. The colon wall which is surrounded by the lumen, intima, convoluted single-layered cubic epithelium, Malpighian tubules and sheath (H\&E) (LM). Abbreviations: ae-aedeagus, clcolon, ep-epithelium, tr-trachea, in-intima, lu-lumen, mt-Malpighian tubules, nu-nucleus, rc-rectum, sh-sheath, tl-tracheole.
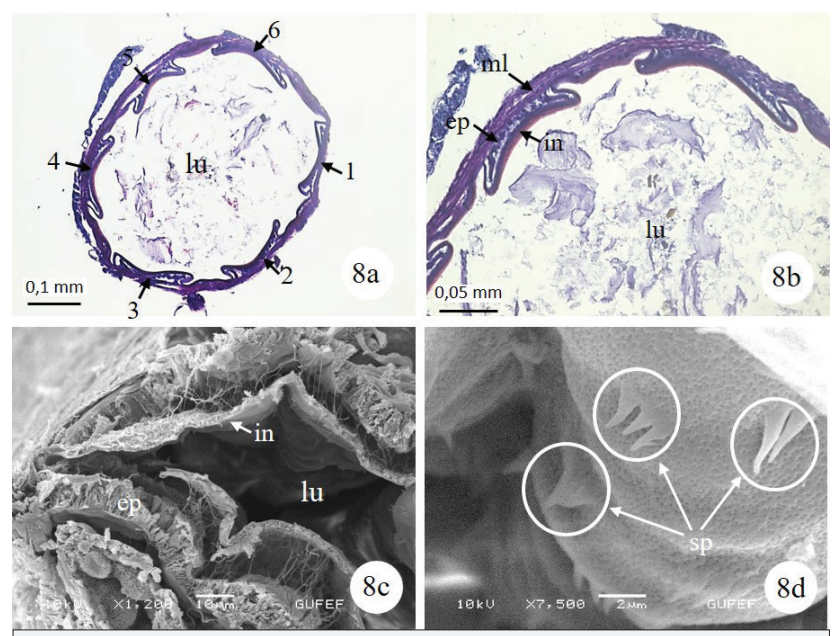

Figure 8. Light microscopy and SEM photographs of the rectum in $M$. picta decastigma. a. The general view of the six rectal pads located on the inner surface of the wall of the rectum (H\&E) (LM). b, c. Intima, monolayer cubic epithelium and muscle layer which are surrounding the rectum wall (H\&E) (LM). d. SEM photograph of spines in groups of two or three in the intima. Abbreviations: 1-6-rectal pads, ep-epithelium, in-intima, lu-lumen, ml-muscle layer, sp-spine.

The colon connected the ileum with the rectum. In the cross section, the rectum lumen consisted of intima, a single layer of cubic epithelium and a muscle layer (Figures $8 a$ and b). There were six rectal pads located on the inner surface of the wall of the rectum (Figure 8a). These pads were composed of cubic cells with round nuclei (Figures $8 \mathrm{~b}$ and $\mathrm{c}$ ). The intima had protrusions in the form of spines in groups of two or three (Figure $8 d)$. The muscle layers lay immediately outside the epithelial layer. When comparing the rectum, ileum and colon, the first had a convoluted cuticular lining and a thick muscular wall, but its lumen was larger than the others (Figures $6 d, 7 c$ and $8 b$ ).

\section{DISCUSSION}

Insects use many different food sources. Therefore, the structure and function of insect guts is bewilderingly diverse (14). The gut is the most universally conspicuous internal organ of insects and is considerably longer than the body. Its structure varies greatly with different foods and different eating habits of insects (17).

The digestive system in general, is similar to that found in other coleopterous insects, and it consists of 3 parts in insects; foregut, midgut and hindgut, and the lengths of these 3 regions vary according to the species (19-24). In M. picta decastigma adults, the foregut and hindgut are almost equal in length, but the midgut is shorter than the other parts. In Adalia bipunctata (Linnaeus) (Coccinellidae), the foregut is the shortest region of the gut (12). The foregut of Asaphes memnonius Hbst. (Elateridae) comprises about one-thirteenth of the total length of the alimentary canal and the length of each midgut and hindgut is approximately one-half the entire length (25). The hind-intestine is approximately two-thirds as long as the body in Penthe 
pimelia (Fabricius, 1801) (Tetratomidae) (20). The midgut of Epicauta cinerea marginata Fab. (Meloidae) occupies about onefourth the entire canal (9).

The foregut of M. picta decastigma distinguishes a pharynx, esophagus, crop and proventriculus. In Phanaeus vindex Macleay (Scarabaeidae), no crop or gizzard is present (19). In A. memnonius (Elateridae), the foregut consists of pharynx and crop (25). The foregut in Phyllophaga gracilis (Burmeister, 1855) (Scarabaeidae) and Crioceris asparagi (L.) (Chrysomelidae) consists of the following regions: pharynx, esophagus, crop, and esophageal valve $(22,23)$. The foregut in P. pimelia (Dacnidae) consists of the mouth, the pharynx, the esophagus, and terminates at the esophageal valve (20).

In the esophagus intima, there are no spines in some species while in other species, different protrusions were seen. On the inner surface of the intima of the esophagus in $M$. picta decastigma, there were sometimes protrusions in the form of spines, sometimes in the form of blunt-tipped teeth. The spines have been observed within the esophageal intima in Alphitobius diaperinus Panzer, 1797 (Tenebrionidae), Dendroctonus micans (Kugelann, 1794), D. ponderosae (Hopkins, 1902), D. pseudotsugae pseudotsugae Hopk., D. rufipennis (Kirby, 1837 ) and $D$. terebrans (Olivier) (Scolytidae) $(10,26)$. There are no spines in the esophagus intima of $P$. vindex (Scarabaeidae) and Platynotus belli Fairmere (Tenebrionidae) $(19,27)$.

Trachelizus bisulcatus (Fabricius) (Brentidae), Allaeometrus breviceps Senna (Brentidae) and Calendyma chilensis (Spinola 1849) (Cleridae), Tanymecus dilaticollis Gyllenhal, 1834 (Curculionidae) have a well-developed proventriculus, but it is weakly developed in M. picta decastigma (Buprestidae), Aporhina australis (Heller) (Brentidae), Mecysolobus bubo (Fabricius) (Curculionidae), Tillus elongatus (Linnaeus) (Cleridae) and Onychotillus vittatus Chapin (Cleridae) (28-30).

In M. picta decastigma, teeth lined up in groups were seen on the inner surface of proventriculus intima, like in Capnodis tenebrionis (L. 1758) (Buprestidae) (3). In Dendroctonus armandi Tsai and Li (Curculionidae), Sitophilus zeamais Motschulsky, 1855 (Curculionidae), Epiphaneus malachiticus Boheman, 1842 (Coleoptera: Curculionidae) and T. dilaticollis (Curculionidae), the proventriculus consists of eight heavily sclerotized chitinous basal plates (29,31-33).

The gastric caeca position, number, and arrangement vary among coleopteran species $(28,34)$. In M. picta decastigma, the midgut has a pair of tubular gastric caeca at the anterior end, as in Capnodis tenebrionis (L. 1758) (Buprestidae) (3). In the posterior midgut of Hypothenemus hampei (Ferrari) (Curculionidae) and in the anterior portion of the midgut in A. bipunctata, two gastric caeca are seen $(12,34)$. D. armandi (Curculionidae) has approximately 160 gastric caeca in the middle of the midgut (32). In the middle of the posterior midgut of E. malachiticus (Curculionidae), there are a lot of gastric caeca (31). However, unlike these species, there is no clear intestinal caeca in the midgut of A. diaperinus (Tenebrionidae) and Epilachna chrysomelina
(Fabricius) (Coleoptera: Coccinellidae) $(35,36)$. They are responsible for secretion and absorption (37). The midgut of Calosoma sycophanta Linnaeus, 1758 (Carabidae) has numerous closely packed small villus-like caeca (37).

There are regenerative crypts surrounding the midgut of $M$. picta decastigma. They are suppliers of new cells to the midgut epithelial lining. Similar structures are seen in P. vindex (Scarabaeidae), P. pimelia (Dacnidae) and Prostephanus truncatus (Horn) (Bostrichidae) $(19,20,17)$. In M. picta decastigma, the midgut epithelium is monolayered columnar cells, as in other species $(32,38)$.

The proximal ends of the six Malpighian tubules are located between mid and hindgut in M. picta decastigma, and they are divisible into two groups: the first group consisting of four tubules and the second consisting of two tubules. Similarly, in C. asparagi (Chrysomelidae) and P. pimelia (Dacnidae), the Malpighian tubules are six in number and are attached to the canal at the pyloric valve $(20,22)$. However, the four Malpighian tubules arise at the posterior end of the foregut in $P$. vindex (Scarabaeidae) (19). The Malpighian tubules of $A$. memnonius (Coleoptera: Elateridae) are four in number and are attached at four different points around the circumference of the gut (25). In M. picta decastigma, histologically they are composed of large cells with large and oval nuclei. Similar structures have been observed in other Coleopteran species $(26,31,32,34-$ $36,38-40)$.

The hindgut in M. picta decastigma is made up of the following regions, pyloric valve, ileum, colon, and rectum as with most other species (20-22,31,35,40). In A. diaperinus (Tenebrionidae), the hindgut is divided into two distinct sections, the anterior small intestine and the posterior large intestine (36). The hindgut in A. bipunctata consists of the ileum, rectum and rectal canal (12).

Ileum epithelial cells in M. picta decastigma are cubic. However, columnar cells constitute the epithelial layer in the ileum of $P$. vindex (Scarabaeidae) (19). In M. picta decastigma, the intima in the ileum has spines. There are spines in the ileum intima of $C$. sycophanta (37).

In M. picta decastigma, the distal ends of the Malpighian tubules also form a layer around the colon as in C. asparagi (Chrysomelidae) (22). However, in P. truncatus, the distal ends of the Malpighian tubules are located in the rectum. They have the same cryptonephric system (17).

There are six rectal pads located on the inner surface of the wall of the rectum of $M$. picta decastigma. A similar structure is also seen in C. sycophanta (37).

\section{CONCLUSION}

In the present study, the anatomy and histology of the alimentary tract of $M$. picta decastigma were examined. These results were compared with those of other species of Coleoptera. It is 
hoped that this study will contribute to the knowledge of the digestive system of other Coleopteran species and other insect species. Furthermore, it is hoped that the characteristics revealed may provide information for future research into the ecology and biological control of noxious Coleoptera.

Peer-review: Externally peer-reviewed.

Conflict of Interest: The authors declare that they have no conflicts of interest to disclose.

Financial Disclosure: There are no funders to report for this submission.

Authors Contributions: Conception/Design of study: N.O.K., U.C., S.C.; Data Acquisition: N.O.K., U.C., S.C.; Data Analysis/Interpretation: N.O.K., U.C., S.C.; Drafting Manuscript: N.O.K., U.C., S.C.; Critical Revision of Manuscript: N.O.K., U.C., S.C; Final Approval and Accountability: N.O.K., U.C., S.C.

Acknowledgements: We express our thanks to Gazi University Academic Writing and Research Center for their help and support in the proofreading of the current study.

\section{REFERENCES}

1. Bellamy CL. A catalogue of the higher taxa of the family Buprestidae (Coleoptera). Navorsinge van die Nasionale Museum, Bloemfontein 1985;4(15):405-72.

2. Bíly S. Summary of the bionomy of the buprestid beetles of central Europe (Coleoptera: Buprestidae). Acta Entomologica Musaei Nationalis Pragae, Supplement 2002;10:1-104.

3. Özyurt Koçakoğlu N, Candan S, Çağlar Ü. Histomorphology of the adult digestive tract of Capnodis tenebrionis (L. 1758) (Coleoptera, Buprestidae). Microsc Microanal 2020;26(6):1245-54. doi:10.1017/ S1431927620024472

4. Foottit RG, Adler, PH. Insect biodiversity: Science and society, Blackwell Publishing, West Sussex, UK, 2009.

5. Sakalian V, Langourov M. Color trap a method for distributional and ecological investigations of Buprestidae (Coleoptera). Acta Soc Zool Bohem 2004;68:53-9.

6. Çanakçıŏlu H. Orman Entomolojisi. i..Ü. Orman Fakültesi Yayınları, i.Ü. Yay. No: 3152, Orman Fak. Yay. No: 349, İstanbul, Birinci baskı, Matbaa Teknisyenleri Basımevi; 1983.

7. Schmitz $\mathrm{H}$, Bousack $\mathrm{H}$. Modelling a historic oil-tank fire allows an estimation of the sensitivity of the infrared receptors in Pyrophilous melanophila beetles. Plos One 2012;7(5):e37627.

8. Bily S. The Buprestidae (Coleoptera) of Fennoscandia and Denmark. Fauna Entomol Scand 1982;110:1-109.

9. Evans HF, Moraal LG, Pajares JA. Biology, ecology and economic importance of Buprestidae and Cerambycidae. Lieutier KRD F, Battisti A, Grégoire J-C, Evans HF, editors. Bark and wood boring insects in living trees in europe, a synthesis. Dordrecht: Springer; 2007. pp. 447-74.

10. Liu XD, Jia XZ. A grey related analysis Cytospora chrysosperma with Melanophila decastigma of poplar. Forest Pest and Disease 1988;4:26-7.

11. Khabir ZH \& Sadeghi SE. Determination of Melanophila picta Pall. (Coleoptera: Buprestidae) damage rate in Populus alba/Medicago sativa agroforestry system. Mun Ent Zool 2012;7(2):920-5.
12. Borges I, Nóia M, Camarinho R, Rodrigues AS, Soares AO. Characterization of the alimentary canal of the aphidophagous ladybird, Adalia bipunctata (Coleoptera: Coccinellidae): anatomical and histological approaches. Entomol Sci 2015;18(1):66-73.

13. Chapman RF. Comprehensive and insect physiology. Kerkut GA, Gilbert LI editors. Biochemistry and Pharmacology. Oxford Pergamon, 1985.

14. Dow JA. Insect midgut function. Adv In Insect Phys 1986;19;187328.

15. Gullan DJ, Cranston PS. The Insects: An outline of entomology, 3rd edn, Blackwell Publishing Ltd, Melbourne, 2005.

16. Wigglesworth VB. The Principles of insect physiology. Chapman and Hall Ltd, London, 1977.

17. Vazquez-Arista M. Anatomical, enzymatic, and microbiological studies on the digestive system of Prostephanus truncatus (Horn), Doctoral thesis, University of Leicester, England, 1997.

18. Gardner JA. Revision of the higher categories of Stigmoderini (Coleoptera: Buprestidae), The University of Adelaide, South Australia, Doctoral thesis, 1986.

19. Bection Jr, EM. The alimentary tract of Phanaeus vindex Macl. (Scarabaeidæ). Ohio J Sci 1930;30(5):315-23.

20. Brubaker RW. The alimentary tract of Penthe Pimelia, Fabr. (Coleoptera: Dacnidae). Ohio J Sci 1934;34(1):46-56.

21. Everly RT. The alimentary tract of the margined blister beetle, Epicauta cinerea marginata Fab. (Coleoptera-Meloidae). Ohio J Sci 1936;36(4):204-16.

22. Davidson RH. The alimentary canal of Criocerus asparagi Linn. Ohio J Sci 1931;31(5):396-405.

23. Fletcher FW. The alimentary canal of Phyllophaga gracilis Burm. Ohio J Sci 1930;30(2):109-19.

24. Lewis HC. The alimentary canal of Passalus. Ohio J Sci 1926;26(1):1124.

25. Bigham JT. The alimentary canal of Asaphes memnonius Hbst. Ohio J Sci 1931;31(5):386-95.

26. Díaz E, Arciniega O, Sánchez L, Cisneros R, Zúñiga G. Anatomical and histological comparison of the alimentary canal of Dendroctonus micans, D. ponderosae, D. pseudotsugae pseudotsugae, $D$. rufipennis, and $D$. terebrans (Coleoptera: Scolytidae). Ann Entomol Soc Am 2003;96(2):144-52.

27. Sarwade AB, Bhawane GP. Anatomical and histological structure of alimentary canal of adult Platynotus belli (Coleoptera: Tenebrionidae). BFAIJ 2013;5:47-55.

28. Calder AA. The alimentary canal and nervous system of Curculionoidea (Coleoptera): Gross morphology and systematic significance. J Nat Hist 1989;23(6):1205-65.

29. Candan S, Özyurt Koçakoğlu N, Güllü M, Çağlar Ü. Anatomical and histological studies of the alimentary canal of adult maize leaf weevil, Tanymecusdilaticollis Gyllenhal, 1834 (Coleoptera: Curculionidae). Microsc Res Tech 2020;83:1153-62.

30. Opitz W. Morphologic studies of the alimentary canal and internal reproductive organs of the Chaetosomatidae and the Cleridae (Coleoptera: Cleroidea) with comparative morphology and taxonomic analyses. Insecta Mundi 2014;0342:1-40.

31. Candan S, Özyurt Koçakoğlu N, Erbey M. Morphology and histology of the alimentary canal of Epiphaneus malachiticus Boheman, 1842 (Coleoptera, Curculionidae). Entomol Rev 2019;99(3):326-36.

32. $\mathrm{Bu} \mathrm{SH}$, Chen $\mathrm{H}$. The alimentary canal of Dendroctonus armandi Tsai and Li (Coleoptera: Curculionidae: Scolytinae). Coleopts Bull 2009;63(4):485-96.

33. De Sousa G, Scudeler EL, Abrahão J, Conte H. Functional morphology of the crop and proventriculus of Sitophilus zeamais (Coleoptera: Curculionidae). Ann Entomol Soc Am 2013;106(6):846-52. 
34. Rubio JDG, Bustillo PAE, Vallejo ELF, Acuña ZJR, Benavides MP AIimentary canal and reproductive tract of Hypothenemus hampei (Ferrari) (Coleoptera: Curculionidae, Scolytinae). Neotrop Entomol 2008;37(2):143-51.

35. Aldigail SA, Alsaggaff Al, Al-Azab AM. Anatomical and histological study on the digestive tract of Epilachna chrysomelina (Coleoptera: Coccinellidae). Biosci Biotechnol Res 2013;10(1):183-92.

36. McAllister JC, Steelman CD, Carlton CE. Histomorphology of the larval and adult digestive systems of Alphitobius diaperinus (Coleoptera: Tenebrionidae). J Kansas Entomol Soc 1995;195-205.

37. Bess HA. The alimentary canal of Calosoma sycophanta Linnaeus. Ohio J Sci 1935;35:54-61.
38. Díaz E, Cisneros R, Zúñiga G. Comparative anatomical and histological Study of the alimentary canal of the Dendroctonus frontalis (Coleoptera: Scolytidae) Comp Ann Entomol Soc Am 2000;93(2): 303-11.

39. Singh $\mathrm{OL}$, Prasad B. Histomorphology of the alimentary tract of adult, Odoiporus longicollis (Oliv.) (Coleoptera: Curculionidae). J Entomol Res Soc 2013;1:109-15.

40. Sinha RN. The alimentary canal of the adult of Tribolium castaneum Herbst (Coleoptera, Tenebrionidae). J Kansas Entomol Soc, 1958;31(2);118-25. 